\title{
An analysis of trends, frequencies and factors influencing the development of resistance to phosphine in the red flour beetle Tribolium castaneum (Herbst) in Australia
}

\author{
Manoj K. Nayak a, e, *, Matthew G. Falk ${ }^{b}$, Robert N. Emery ${ }^{\text {c, e }}$, Patrick J. Collins ${ }^{\text {a, e }}$, \\ Joanne C. Holloway ${ }^{\mathrm{d}} \mathrm{e}$ \\ ${ }^{a}$ Department of Agriculture and Fisheries, Queensland, Ecosciences Precinct, GPO Box 267, Brisbane, QLD 4001, Australia \\ b Department of Mathematical Sciences, Queensland University of Technology, Australia \\ c Department of Agriculture and Food, South Perth, Australia \\ d New South Wales Department of Primary Industries, Wagga Wagga Agricultural Institute, Wagga Wagga, Australia \\ e Plant Biosecurity Cooperative Research Centre, GPO Box 5012, Bruce, ACT 2617, Australia
}

\section{A R T I C L E I N F O}

\section{Article history:}

Received 6 December 2016

Received in revised form

23 March 2017

Accepted 23 March 2017

\section{Keywords:}

Phosphine

Stored grain

Resistance monitoring

Bayesian hurdle model

\begin{abstract}
A B S T R A C T
Although resistance to phosphine, the key disinfestant used worldwide in the stored grain environment has been an ongoing industry issue, studies on its trend over large geographic region and over long period of time is very limited. In this study, we critically analysed 20 years' phosphine resistance diagnosis data for the red flour beetle Tribolium castaneum (Herbst) stored in the Australian Grain Insect Resistance Database. Resistance diagnosis on a staggering 6336 samples, along with information on storage types and treatment history was interrogated to establish trends and frequencies of resistance development in this species and factors that may have contributed towards these resistance occurences. Using descriptive statistics, linear and trend analysis and a well established Bayesian hurdle model, we determined that strong resistance in $T$. castaneum was significantly more prevalent in quarantine intereceptions than in central storages and on farms. The strong resistance incidences had been confined to eastern states of Queensland, New South Wales, Victoria and South Australia, whereas it is yet to be detected in the state of Western Australia. We could not establish any significant correlation between the strong resistance development and any commodity or treatments. After an initial increasing trend in incidences since the first detection of strong resistance in 1997 in this species, the frequency was stabilised during 2001-08; after which there had been an upward trend since 2009 till the last survey in 2013. The conclusions derived from this analyses highlighted the importance of a resistance monitoring program with relevant information being used in Australia as the basis for ongoing and future phosphine resistance management strategies. This research may also proved valuable towards devising similar strategies in overseas countries with phosphine resistance problems.
\end{abstract}

Crown Copyright $\odot 2017$ Published by Elsevier Ltd. All rights reserved.

\section{Introduction}

Fumigation with phosphine has been the main method used to disinfest stored grain across the globe for several decades. Development of strong levels of resistance in key pest species has threatened to jeopardise the viability of this unique fumigant that is considered to be the cheapest and most versatile among all

\footnotetext{
* Corresponding author. Department of Agriculture and Fisheries, Queensland, Ecosciences Precinct, GPO Box 267, Brisbane, QLD 4001, Australia.

E-mail address: manoj.nayak@daf.qld.gov.au (M.K. Nayak).
}

available fumigants, as well as accepted as a residue-free treatment (Nayak et al., 2016). Due to a lack of suitable alternatives that match the enviable characteristics of phosphine, managing resistance to phosphine has been an ongoing priority for the industry. A key component of any phosphine resistance management program is the early and accurate detection of the resistance, followed by its characterisation and intervention (Nayak et al., 2015). In recent years, there has been growing interest around the world in the diagnosis and characterisation of phosphine resistance in key stored grain pest species (Lorini et al., 2007; Nayak et al., 2012; Opit et al., 2012; Kaur et al., 2015; Chen et al., 2015; Koçak et al., 2015; Daglish et al., 2014, 2015). Australia has a unique phosphine 
resistance monitoring program that surveys both farms and bulk grain storages across the country on a regular basis. Since its inception in the 1990s, this program has been instrumental in detection of new instances of resistance as they developed in the field (Emery et al., 2011). Apart from being an early warning system for resistance developments, the monitoring program has been an ongoing source of valuable insect materials for resistance management research. This has enabled Australia to establish both bioassay and molecular diagnostic methods to detect two levels of resistance (weak and strong) in all major storage pests (Emery et al., 2011) and develop new fumigation protocols to manage strongly resistant populations (Collins et al., 2005; Kaur and Nayak, 2015).

Underpinning a well-coordinated national resistance monitoring program, an internet-based database has also been established for keeping the records of resistance detections across Australia (Emery and Tassone, 1998). The Australian Grain Insect Resistance Database (AGIRD) is accessed by researchers in three dedicated laboratories across Australia (Brisbane in Queensland, Wagga Wagga in New South Wales and Perth in Western Australia). Resistance data on field-collected insect samples with both weak and strong levels of resistance are entered into AGIRD as they are diagnosed. Several aspects on the origin of each individual insect sample including the geographic location, storage type, commodity and treatment history are also recorded. This database has enabled us to critically analyse and map resistance incidents over the years and to develop appropriate management strategies to contain and eradicate strongly resistant populations (Emery et al., 2011). Currently, AGIRD holds information on approximately 40,000 insect population samples belonging to five major pests, Rhyzopertha dominica (F.), Tribolium castaneum (Herbst), Sitophilus oryzae (L.), Cryptolestes ferrugineus (Stephens) and Oryzaephilus surinamensis (L.). These samples were collected from approximately 11,000 storage sites across the grain growing areas in Australia.

Although there are numerous reports available in the literature on the detection of phosphine resistance in key stored grain pests across the globe, analysis of country-wide resistance trends and frequencies have been limited to only two reports (Holloway et al., 2016; Collins et al., 2017). Falk et al. (2014) used standard exploratory statistics methods on a subset of data stored in AGIRD and established a hurdle model that fits appropriately to give us insight into important events such as development of strong resistance to phosphine in key pest species. Since then, the model has been successfully applied to AGIRD data accumulated over two decades to critically analyse resistance developments in two key pest species, S. oryzae (Holloway et al., 2016) and R. dominica (Collins et al., 2017).

This paper, as part of ongoing research involving further data mining of the AGIRD, will attempt to deal with the cosmopolitan pest, the red flour beetle $T$. castaneum. In addition to establishing the trends and frequencies of phosphine resistance over the last two decades, we will critically analyse several factors involved in grain storage practices across Australia in order to identify those that have contributed towards such resistance trends. Emphasis will be given to occurrences of strong resistance, although the data on weak resistance will be presented. Critical findings from this research will be used strategically towards developing broader pest and resistance management programs for grain storage systems across Australia and overseas countries where phosphine resistance is a problem.

\section{Materials and methods}

\subsection{Collection of insect samples}

Insect population samples were mostly collected from farms, central storages, merchants and grain processors by technical staff located at three laboratories representing their respective grain growing regions: Northern (Brisbane, Queensland), Southern (Wagga Wagga, New South Wales) and Western (Perth, Western Australia). In general, grain and residues were sampled by using a sieve or a commercially designed spear. Insect samples were placed in plastic containers, along with some grain or feed material, and lids with small holes and filter paper fitted underneath to facilitate air passage during transport in order to avoid mortality. For overnight travels, the samples were kept in eskies (foam containers) to avoid mortality of insects due to high temperature. In addition, insect samples intercepted at quarantine and insects surviving from control failures at central storages and some farms were sent directly to the laboratory for resistance diagnosis. Such samples were sent by overnight courier services to ensure survival of insects and rapid processing.

A nationally-agreed resistance monitoring protocol was followed for each region, where an information sheet was filled for each collected sample that contained vital information including the date of collection, geographic location (latitude and longitude), storage type, commodity and treatment history. In cases where there were multiple storages, several samples may have been collected. Due to the possibility of different conditions, treatment or commodity, these samples were maintained as separate populations. If an insect population in a sample was diagnosed as 'strong resistant' (see below), then advice was sent to the relevant grain storage operator to undertake remedial action. A few weeks after such advice, attempts were made for the collection and resistance diagnosis of a follow up insect sample from the same storage to assess the impact of the remedial action.

\subsection{Phosphine resistance diagnosis}

After the receival of field samples at the laboratory, the insects were sorted to species. T. castaneum adult populations collected from different storages were marked individually as field strains with unique codes for their entry in the AGIRD database for future reference and cultured on a diet of wholemeal flour plus $2 \%$ yeast at laboratory regimes of $27-30^{\circ} \mathrm{C}$ and $55-60 \% \mathrm{RH}$. The first generation adult progeny (1-2 weeks post eclosion) from these cultures were tested for resistance to phosphine following the bioassay method described by Holloway et al. (2016).

Briefly, for each designated field strain, batches of 50 unsexed adult $T$. castaneum were placed with a small amount of flour in plastic cups $(25 \mathrm{~mL})$ fitted with perforated lids. Three replicates were organised for each strain for testing at each of the two discriminating dosages: a lower dose of $0.03 \mathrm{mgL}^{-1}$ and a higher dose of $0.25 \mathrm{mgL}^{-1}$ of phosphine, over an exposure period of $20 \mathrm{~h}$ for diagnosing weak and strong levels of resistance, respectively. These dosages were modified by White and Lambkin (1990) from the original FAO method (FAO, 1975) to diagnose the two levels of resistance to phosphine. Three replicates were also set up for control that did not receive phosphine fumigation. Batches of adults from laboratory reference strains characterised as susceptible, weak and strong resistant were included in all test vessels for validation of the diagnosis of the field strains. Survivors diagnosed as 'strong resistant' in a strain were further cultured and retested for confirmation and in some cases, validated through a test in collaborating laboratory to ensure the integrity of the results.

The experimental cups with insects were placed in gas tight desiccators and the required phosphine gas, generated from a commercial formulation of aluminium phosphide was injected through a septum into the desiccators following an established bioassay method (FAO, 1975). After fumigation, all desiccators were held in a controlled temperature room at regimes of $25^{\circ} \mathrm{C}$ and $55 \%$ 
$\mathrm{RH}$ for a period of $20 \mathrm{~h}$. After $20 \mathrm{~h}$, the desiccators were opened under a fume hood, insects from all experimental and control cups were removed, some fresh flour provided to the insects and the cups were returned to the controlled temperature room and left for recovery over seven days at $25^{\circ} \mathrm{C}$ and $55 \% \mathrm{RH}$. Mortality was assessed at the end of seven days and individual strains were diagnosed as either susceptible (if there was no survival), weak resistant (some individuals survived $0.03 \mathrm{mgL}^{-1}$, but none survived $0.25 \mathrm{mgL}^{-1}$ ) or strong resistant (if individuals survived $0.25 \mathrm{mgL}^{-1}$ ).

\subsection{Australian grain insect resistance database (AGIRD)}

Data entered into AGIRD by each of the three collaborating laboratories are accessed by each of the custodians and information being shared and analysed at regular intervals, and presented to industry at the annual Australian Grain Storage and Protection Conference.

Substantial synchronisation and cleaning of the AGIRD was undertaken prior to the current analysis that involved removal of duplicate strains, geocoding sites with a focus on considering records of bioassays related to the correct dose-exposure combination for determining weak and strong resistances (see above). Here, we present synthesised data for strong and weak resistance diagnoses in T. castaneum from a final dataset that contained 6336 and 6265 unique observations, respectively. The datasets cover resistance diagnosis of samples collected over the 1995-2013 period.

The variables considered in the analysis are binary responses indicating presence or absence of strong resistance, commodity, state, area within state, site type, storage type and 16 binary variables indicating whether or not a particular treatment was applied to the grain storage. Given the high proportion of weak resistance, only its presence or absence and the date collected were the variables considered for analysis.

\subsection{Statistical analysis and Bayesian hurdle model}

The raw data for both weak and strong resistance diagnoses were subjected to multi-step statistical analyses with descriptive statistics, standard parametric tests and linear and smooth trend analysis using the $\mathrm{R}$ statistical software (R Core Team, 2015). In parallel, a Generalised Additive Model (GAM) was used to fit a smoothed curve for the trend using the R package MGCV (Wood, 2006). Finally, a Bayesian hurdle model (Falk et al., 2014) was applied to the dataset to establish trends in resistance levels (weak and strong), and significant variables that have specifically contributed towards development of strong resistance to phosphine. The key advantage of using this model was to overcome the problem of lowering of the explanatory power of logistic and probit regressions due to the large number of absences in the dataset compared to the number of presences, specifically in the response variable (eg. presence or absence of strong resistance). Briefly, the Bayesian hurdle model approaches this by assuming that there were two processes influencing resistance response; one generating excess zeros indicating absences and the other generating the remaining presences and absences related to specific conditional distribution. In the first step, the model used a Bayesian Classification and Regression tree (BCART), as described by O'Leary (2008) and coded in $\mathrm{R}$, to determine those profiles of variables that have led to the possibility of presence of resistance. The second step narrows it down further and focuses on where the hurdle is crossed' (variables and variable combinations that have led to the possibility of presence of strong resistance) and then uses GAMs to fit trends and search for significant influential variables over time that led to the development of strong resistance (Scheipl, 2011).
This application allowed us to avoid the masking of trend and effects of influential variables by the large number of absences of strong resistant observations in the dataset.

\section{Results}

\subsection{Descriptive statistics}

Data presented here are based on utilisation of exploratory data analyses to gauge what can be determined and described from the raw data. Tables presented below indicate the proportion of strong resistance only for the different levels of each of the variables (Tables 1 and 2). Both raw percentages and normalised percentages (raw data percentages adjusted so that the sum of individual percentages becomes 100) are presented to give the overall scenario. Of the final dataset containing 6336 unique observations recorded from samples collected and diagnosed across Australia, 62 samples of $T$. castaneum indicated the presence of strong resistance. The descriptive statistics of the detection of strong resistance over the 1995-2013 period is presented below under each relevant variable.

\subsubsection{Site}

The number of samples of $T$. castaneum collected from storages in different types of sites is listed in Table 1, which mainly includes

\section{Table 1}

Number of samples of $T$. castaneum collected under each category and the percentage samples diagnosed with strong resistance to phosphine. 'Raw' data has not been subjected to any processing or manipulation, whereas 'Normalised' data adjusts the raw data percentages so that the sum of individual percentages becomes 100

\begin{tabular}{|c|c|c|c|}
\hline \multirow[t]{2}{*}{ Variables } & \multirow{2}{*}{$\begin{array}{l}\text { Number of } \\
\text { samples } \\
\text { tested }\end{array}$} & \multicolumn{2}{|c|}{$\begin{array}{l}\% \text { Samples diagnosed with strong } \\
\text { resistance }\end{array}$} \\
\hline & & Raw & Normalised \\
\hline \multicolumn{4}{|l|}{ Site type } \\
\hline Central storage & 862 & 1.4 & $4.56 \mathrm{a}^{*}$ \\
\hline Farm & 5208 & 0.8 & $2.60 \mathrm{ab}$ \\
\hline Feed lot & 12 & 0 & $0.00 \mathrm{a} \mathrm{b} \mathrm{c}$ \\
\hline Flour mill & 43 & 7 & 22.80 a c \\
\hline Merchant & 154 & 3.3 & 10.76 a c \\
\hline Quarantine & 11 & 18.2 & $59.28 \mathrm{c}$ \\
\hline Research station & 33 & 0 & 0.00 a b c \\
\hline Unknown & 13 & 0 & $0.00 \mathrm{a} \mathrm{b} \mathrm{c}$ \\
\hline \multicolumn{4}{|l|}{ Storage type } \\
\hline A - aerated & 4 & 0 & $0.00 a^{*}$ \\
\hline B - bunker & 48 & 2 & $34.49 \mathrm{a} b$ \\
\hline D - shed & 43 & 0 & $0.00 \mathrm{a} \mathrm{b} \mathrm{c}$ \\
\hline $\mathrm{H}$ - household & 6 & 0 & 0.00 a b c d \\
\hline I - silo & 641 & 1.8 & $31.03 \mathrm{abcde}$ \\
\hline $\mathrm{N}-$ unknown & 1113 & 0.2 & $3.45 \mathrm{a} \mathrm{bc} \mathrm{df}$ \\
\hline $\mathrm{S}$ - sealed & 702 & 0.6 & 10.35 a b c d ef \\
\hline $\mathrm{U}$ - unsealed & 3779 & 1.2 & 20.68 a b c def \\
\hline \multicolumn{4}{|l|}{ Commodity type } \\
\hline 2 - barley & 1081 & 1.8 & $6.93^{* *}$ \\
\hline 22 - lupins & 72 & 2.8 & 10.77 \\
\hline 25 - mixed grain & 106 & 2 & 7.70 \\
\hline 27 - oats & 1503 & 0.8 & 3.07 \\
\hline $\begin{array}{l}34 \text { - processed } \\
\text { food }\end{array}$ & 29 & 7 & 26.93 \\
\hline 35 - sorghum & 223 & 0.5 & 1.92 \\
\hline 38 - unknown & 913 & 0.3 & 1.15 \\
\hline 39 - wheat & 2037 & 0.8 & 3.07 \\
\hline 51 - triticale & 92 & 3 & 11.53 \\
\hline 58 - flour & 15 & 7 & 26.93 \\
\hline
\end{tabular}

* Percent strong resistant phenotypes diagnosed under each category (site type, storage and commodity) were compared within category using Chi-square analysis. Percent diagnosed followed by the same letter are not significantly different, Site: $\left(X^{2}=61.22, p<0.01\right)$, Storage: $\left(X^{2}=13.97, p<0.01\right)$.

**Frequencies and proportions of strong resistance for various commodities are not significantly different $\left(X^{2}=38.70, p=0.12\right)$ and hence no pairwise comparisons are provided. 
Table 2

Number of samples of $T$. castaneum collected in regions of three major grain growing states of Australia and the percentage samples diagnosed with strong resistance to phosphine. 'Raw' data has not been subjected to any processing or manipulation, whereas 'Normalised' data adjusts the raw data percentages so that the sum of individual percentages becomes 100 .

\begin{tabular}{|c|c|c|c|}
\hline \multirow[t]{2}{*}{ State and region } & \multirow[t]{2}{*}{$\begin{array}{l}\text { Number of } \\
\text { samples tested }\end{array}$} & \multicolumn{2}{|c|}{$\begin{array}{l}\text { \% Samples diagnosed with } \\
\text { strong resistance }\end{array}$} \\
\hline & & Raw & Normalised \\
\hline \multicolumn{4}{|l|}{ Queensland } \\
\hline Central QLD & 274 & 3.00 & $68^{*}$ \\
\hline South east QLD - Central & 210 & 1.40 & 32 \\
\hline South east QLD - East & 97 & 0.00 & 0 \\
\hline South east QLD - South & 146 & 0.00 & 0 \\
\hline South east QLD - West & 205 & 0.00 & 0 \\
\hline \multicolumn{4}{|l|}{ New South Wales } \\
\hline Moree & 173 & 1.10 & $3 a^{* *}$ \\
\hline Narrabri & 135 & 1.50 & $4.2 \mathrm{a} \mathrm{b}$ \\
\hline Spring Ridge & 65 & 1.50 & $4.2 \mathrm{a} \mathrm{b} \mathrm{c}$ \\
\hline Dubbo & 193 & 8.30 & 23.3 a b c d \\
\hline Parkes & 128 & 3.10 & $8.8 \mathrm{a} \mathrm{b} \mathrm{c} \mathrm{de}$ \\
\hline Wyalong & 264 & 1.10 & 3 a bce f \\
\hline Cootamundra & 73 & 5.50 & 15.5 a b c d e f g \\
\hline Wagga Wagga & 237 & 1.00 & $2.8 \mathrm{abcde} g$ \\
\hline $\begin{array}{l}\text { NSW Coastal } \\
\text { Victoria }\end{array}$ & 32 & 12.50 & 35.2 a b c d e g \\
\hline North west Mallee & 23 & 0.00 & $0.00^{*}$ \\
\hline Swan Hill/Mallee & 17 & 0.00 & 0.0 \\
\hline $\begin{array}{r}\text { Warracknabeal/ } \\
\text { South Mallee }\end{array}$ & 43 & 0.00 & 0.0 \\
\hline Central VIC & 50 & 4.00 & 26.10 \\
\hline $\begin{array}{l}\text { Echuca/South } \\
\text { Riverina }\end{array}$ & 14 & 0.00 & 0.00 \\
\hline $\begin{array}{l}\text { Yarrawonga/ } \\
\text { North east VIC }\end{array}$ & 24 & 8.30 & 54.14 \\
\hline West Wimmera & 35 & 0.00 & 0.00 \\
\hline Murtoa & 32 & 3.03 & 19.76 \\
\hline
\end{tabular}

*Percent samples diagnosed with strong resistance for different regions within the states of Queensland $\left(X^{2}=10, p=0.265\right)$ and Victoria $\left(X^{2}=8.42, p=0.26\right)$ are not significantly different and hence no pairwise comparisons are provided.

**Percent samples diagnosed with strong resistance within different regions of New South Wales followed by the same letter are not significantly different $\left(X^{2}=41.55\right.$, $p<0.01$ ).

central storages, farms, feed lots, flour mills and merchants. Samples analysed included those collected from quarantine inspections, research stations and samples sent directly to laboratories from unknown sources. Among the two highest sample collections under the farm (5208) and central storage (862) site types, there was no significant difference between the proportion of strong resistance detections of 0.8 and $1.4 \%$, respectively (Table 1 ). However, although the samples collected from quarantine interceptions were the lowest (11) among all site types, the proportion of strong resistance detection was the highest in this category (18.2\%) and was significantly different from the data recorded for farms and central storages $\left(X^{2}=61.22, \mathrm{p}<0.01\right.$ ) (Table 1$)$. There were no detections of strong resistance in samples collected from feed lots, research stations or unknown sources (Table 1).

\subsubsection{Storage}

Within each site visited, the storages from where insect samples were collected was categorised further, this included silos, bunkers, aerated, sealed and unsealed (in relation to gas tightness for fumigation at time of manufacture) (Table 1). Some samples were collected from households and some marked as unknown due to lack of proper description of storage situation. The largest numbers of samples were collected from unsealed storages (3779) followed by storages recorded as unknown (1113); whereas sealed storages and silos both have 700 samples recorded against them (Table 1). At the other end, bunkers and sheds had 48 and 43 samples collected from them, respectively; while samples collected from households and aerated storages were below 10 (Table 1 ).

When both the raw and normalised percentages were considered, the highest percentages of strong resistance were recorded against bunkers, followed by silos and unsealed storages (Table 1 ). There were no detections of strong resistance in storages under the categories of aerated, shed and households. There was no significant difference in percent detections of strong resistance between sealed (0.6\%) and unsealed storages (1.2\%) (Table 1$)$. However, percent strong resistance detection recorded for storages with unknown description (0.2) was significantly different from that recorded for silos $(1.8 \%)\left(X^{2}=13.97, \mathrm{p}=0.02\right)$ (Table 1$)$.

\subsubsection{Commodity}

Samples of $T$. castaneum were collected from a wide range of commodities, which are listed in Table 1 and the Appendix. Wheat was the dominant commodity that harboured T. castaneum (2037 samples) followed by oats (1503 samples) and barley (1081 samples). A very high number of 913 samples were also collected from unknown commodities (Table 1). However, although only a small numbers of $T$. castaneum samples were collected from processed food (29) and flour (15), the highest proportion of strong resistance detections were recorded against both these commodities (7\%). There was no significant difference between proportions of strong resistance detections for various commodities. Therefore, no pairwise comparison was possible between the proportions of strong resistance for the various commodities $\left(X^{2}=38.70, \mathrm{p}=0.12\right)$.

\subsubsection{Treatments}

There were 16 types of pest control treatment recorded against the commodities from where the samples of $T$. castaneum were collected for this study. These include a range of contact insecticides belonging to major groups such as organophosphates, pyrethroids, insect growth regulators and diatomaceous earth as well as phosphine applied as tablets and continuous flow (SIRO$\left.\mathrm{FLO}^{\circledR}\right)$. None of these 16 binary variables indicating specific treatments that were applied to storages, however, were particularly well populated with non-zero values and unsurprisingly, showed no significant correlation with the development of strong resistance in T. castaneum populations across Australia.

\subsubsection{Regions}

Over the 1995-2013 period, no strong phosphine resistance was reported from Western Australia, with 3663 T. castaneum populations tested. This was also the case for the two samples tested from Tasmania and one from Northern Territory. Only one population from the 199 samples collected from South Australia was diagnosed as strongly resistant to phosphine. Due to this single detection in South Australia and non-detection of strong resistance in the states listed above, we only analysed the data gathered on strong resistance diagnosis for $T$. castaneum samples collected from the three major grain growing states of New South Wales, Queensland, and Victoria (Table 2). Depending on the geographic spread and agro-ecological similarity, sites within each state were grouped by region to highlight the prevalence of strong resistance.

Overall, 932 samples of $T$. castaneum were collected from the state of Queensland, of which only 11 (4.4\%) were diagnosed with strong resistance (Table 2). Within this state, central Queensland had the highest proportion of strong resistance detections, with 3\% of the 274 samples returning a positive diagnosis. The next most common region was the central part of southeast Queensland, having $1.4 \%$ of the 210 samples detected with strong resistance (Table 2). No strong resistance was detected in samples collected from any of the other subregions of southeast Queensland: East (97), South (146) and West (205). A Chi-squared test revealed no 
significant differences between strong resistance detections in different regions within Queensland $\left(X^{2}=10, p=0.265\right)$.

In the state of New South Wales (NSW), 1300 samples of. T. castaneum were collected and tested for strong resistance to phosphine over the study period, of which 38 (35.6\%) were diagnosed with strong resistance (Table 2). Wyalong with 264 samples and Wagga Wagga with 237 samples were the leading regions so far as the number of samples collected was concerned; whereas New South Wales coastal region with $12.5 \%$ (of 32 samples) and Dubbo (central NSW) with 8.3\% (of 193 samples) stood out in regard to strong resistance detections (Table 2). A Chi-squared test revealed significant differences between regions $\left(X^{2}=41.55, \mathrm{p}<0.01\right)$ (Table 2).

From the state of Victoria, 238 populations were collected, of which, 5 samples (16\%) returned a positive diagnosis for strong resistance (Table 2). Among the various regions surveyed within this state, the highest number of samples (50) were collected from Central Victoria, followed by 43 from Warracknabeal/South Mallee, 35 from West Wimmera and 32 from Murtoa (Table 2). The highest proportion of strong resistance detections, however, were recorded for the Yarrawong/North East Victoria region (8.3\% of the 24 samples) followed by Central Victoria (4\%) and Murtoa region (3.03\%) (Table 2). Although several other regions recorded numerous populations, returned no detections for strong resistance (Table 2). There was no significant difference between the strong resistance detections recorded across the different regions within Victoria $\left(X^{2}=8.42, p=0.26\right)$.

Although descriptive statistics involving several variables as described above were not performed on samples tested for weak resistance in $T$. castaneum, overall 2546 samples were diagnosed with weak resistance (41\%) across Australia from the dataset of 6265 observations. When compared individually, New South Wales recorded the highest percentage of weak resistance detections (62.5\% of the 1380 samples), followed by Queensland with $57.5 \%$ (1082 samples), South Australia with 54.5\% (233 samples), Victoria with 52.6\% (287 samples) and Western Australia with 25\% (3280). The only sample collected from Northern Territory turned out to be susceptible to phosphine and of the two samples collected from Tasmania, one returned positive for weak resistant, while the other was susceptible to phosphine.

\subsection{Trend analysis}

The trend analysis of the strong resistance detections through time, at a national level showed a slightly significant linear trend $\left(\mathrm{p}=0.1, \mathrm{R}^{2}=11.46 \%\right)$ and a highly significant smoothed trend $\left(\mathrm{p}<0.01, \mathrm{R}^{2}=59.5 \%\right.$ ) (Fig. 1 ). Since the first detection of strong resistance in this species in 1997 in a farm in New South Wales, there have been sporadic detections over the years. The percentage detection remained well below the $2 \%$ level until it suddenly peaked in two successive years 2011-12, during which the overall frequency had gone up to $5 \%$.

As no strong resistance was detected in Western Australia in $T$. castaneum populations tested over the study period, trend analysis was exclusively performed on the raw data collected from the eastern part of Australia (Fig. 2). Like the national trend, the analysis of strong resistance in eastern Australia showed a slightly significant linear trend $\left(\mathrm{p}=0.11, \mathrm{R}^{2}=15.96 \%\right)$ and highly significant smoothed trend ( $\mathrm{p}<0.02, \mathrm{R}^{2}=45.8 \%$ ). Since the first detection of strong resistance in this species in 1997 there have been sporadic detections over the years with the percentage detection remaining well below the $2 \%$ level between the $2000-07$ period, after which, there was a peak in 2007 (4\%) and two peaks during 2011 (12 detections) and 2012 (14 detections) (Fig. 2). During 2011-12 peak period, the overall frequency of strong resistance detection remained approximately around the 5-6\% level.

The national weak resistance trend analysis (Fig. 3), shows a significant linear trend $\left(\mathrm{p}<0.01, \mathrm{R}^{2}=80.03 \%\right)$ and a significant smoothed trend from the GAM ( $p<0.01, \mathrm{R}^{2}=85.7 \%$ ). The percentage of weak resistance detections was around the $20 \%$ level in the early 1990s, but with a steady increase in frequency it reached 50\% during the 2000 and exceeded 90\% in 2011 (Fig. 3).

We also fit trends for weak resistance, dividing the data into eastern (linear $\mathrm{p}<0.01, \mathrm{R}^{2}=89 \%$ and smoothed $\mathrm{p}<0.01$, $\mathrm{R}^{2}=92.8 \%$ ) and western (linear and GAM $\mathrm{p}<0.01, \mathrm{R}^{2}=38.31 \%$ ) segments, both of which showed significant trends for both models (Fig. 4). These analyses clearly established a higher frequency in weak resistance detections in the western region compared with the eastern region through the earlier part of the survey period, but both regions came closer to each other during 2008-2012, where the percent detections approached 100\% (Fig. 4).

\subsection{Bayesian hurdle model}

The Bayesian hurdle model is a two-step approach used to explore links between strong resistance developments and variables listed in the database. The first step uses a Bayesian classification tree (BCART) to partition the observations into nodes with increasing homogeneity as one progresses down the tree. The tree was constructed in a way that provided the most observations classified into nodes without any presence of strong resistance. The BCART for $T$. castaneum showed that the state and commodities were determining factors for strong resistance (Fig. 5). The strong resistance was not present in Western Australia over the survey period, whereas it was present in the States of New South Wales, Queensland, South Australia and Victoria (Fig. 5). The left branch of the tree under these states revealed that stored commodities including canola, chickpea, cotton seed, maize, mung beans, sunflower, peas and safflower have had no specific association with the presence of strong resistance to phosphine in T. castaneum. However, stored commodities wheat, barley, sorghum, lupins, mixed grain, oats, processed food, triticale and flour were strongly associated with the occurrence of strong resistance in this species (Fig. 5). The algorithm for the tree deemed the storage variable to have no significant impact on the incidence of strong resistance in this species, therefore, no node was presented in the tree for this variable.

At step 2 of the hurdle model, a Bayesian generalized additive model (BGAM) with spike and slab priors for variable selection was fitted to those observations identified as having some presence of strong resistance. Convergence of the fitting procedure for the BGAM was assessed using the Rhat diagnostic, with no values substantially above one (Gelman et al., 2003), indicating that the final model closely followed the data. The results presented are model averaged effects of the trend and covariates on the estimated logits (log odds) for strong resistance (and 80\% credible intervals) with categorical covariate levels showing increase or decrease in strong resistance incidence. The results of the BGAM with included predictors as indicated by the spike and slab procedure are presented in Figs. 6-9. The y-axes of outputs of the BGAM (Figs. 6-9) specifies $n$, representing the model average effects of the trend and variables (with 95\% credible intervals). Interpretation of these outputs can be done in a way where values greater than zero indicate a higher incidence, as the expected probability of presence of strong resistance is equal to 0.5 when $\mathrm{n}=0$ holding all else constant.

The BGAM analysis shows that among the different storage sites surveyed, only flour mills and quarantine interception had a significant influence in relation to the incidence of strong resistance to phosphine in T. castaneum (Fig. 6). However, central storages and 


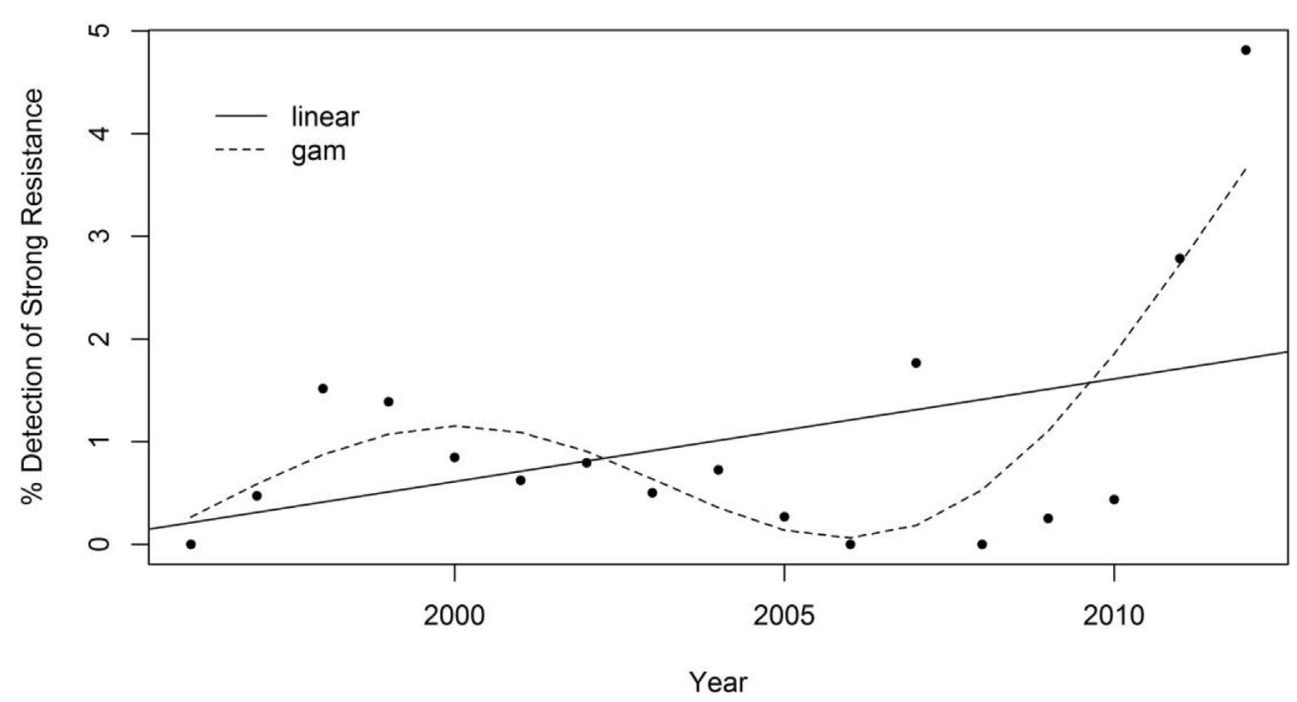

Fig. 1. Linear and smoothed (generalised addition model, GAM) trend analysis of raw strong resistance data aggregated by year collected for T. castaneum across Australia.

farms, where the bulk of samples were collected from, appeared to have less association with the strong resistance developments in view of the lower confidence levels covering zero (Fig. 6).

Among states surveyed, the BGAM analysis showed a much higher trend in strong resistance detections in New South Wales and Queensland than Tasmania and Victoria; whereas the credible intervals covering zero indicated the lower incidence of strong resistance detections in South Australia (Fig. 7). Western Australia did not feature in the graph as there was no detection of strong resistance in this state.

The BGAM analysis for commodities showed a close relationship of strong resistance detection with barley, lupin, oats and triticale; but insignificant association with major commodities including wheat, sorghum and flour (Fig. 8).

The overall trend in strong resistance detection in T. castaneum showed an initial increasing trend during 1998-2000 period, which slowed down and slightly dipped during the 2001-2008 period; after which, there was a rapid upward trend from 2009 till the last survey in 2013 (Fig. 9).

For an overview of both weak and strong resistant detections nationally, a six yearly distribution of populations collected and their resistance diagnosis are presented in Figs. 10-13.

\section{Discussion}

The main aim of this study was to analyse the 20 years of resistance data stored in AGIRD and establish the trends, frequencies and development of phosphine resistance in the cosmopolitan pest T. castaneum across Australia. Several factors involved in the grain storage practices were also critically analysed to identify those that might have contributed towards development of strong resistance. Phosphine resistance surveys of $T$. castaneum have been previously undertaken across wide geographic regions in the USA (Zettler, 1990; Opit et al., 2012), Brazil (Pimental et al., 2010), Morocco (Benhalima et al., 2004), India (Kaur et al., 2015) and Turkey (Koçak et al., 2015). However, so far, no country has presented data on this pest that involved many years of continuous monitoring of field populations for their resistance status. Considering this, the dataset presented here on the trends and frequencies of phosphine resistance in T. castaneum over the last two decades in Australia can be considered as the first of its kind and the most comprehensive study so far for this pest species.

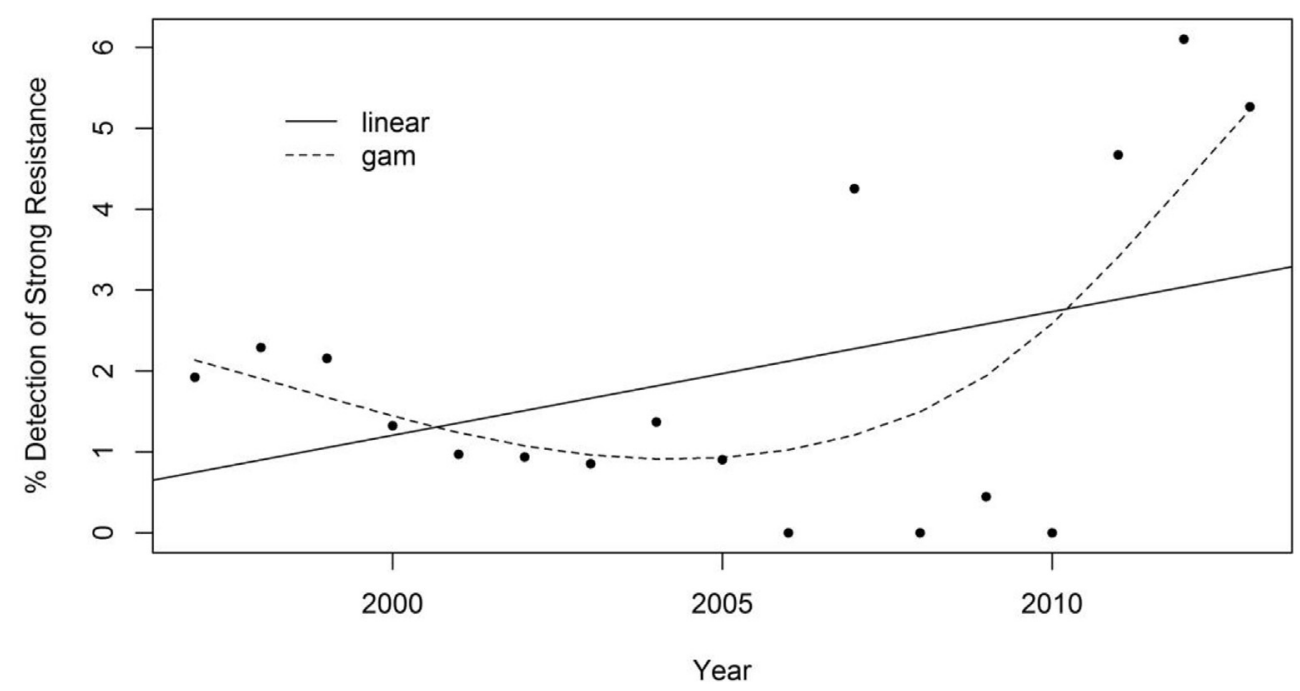

Fig. 2. Linear and smoothed (generalised addition model, GAM) trend analysis of raw strong resistance data aggregated by year collected for T. castaneum across Australia. 


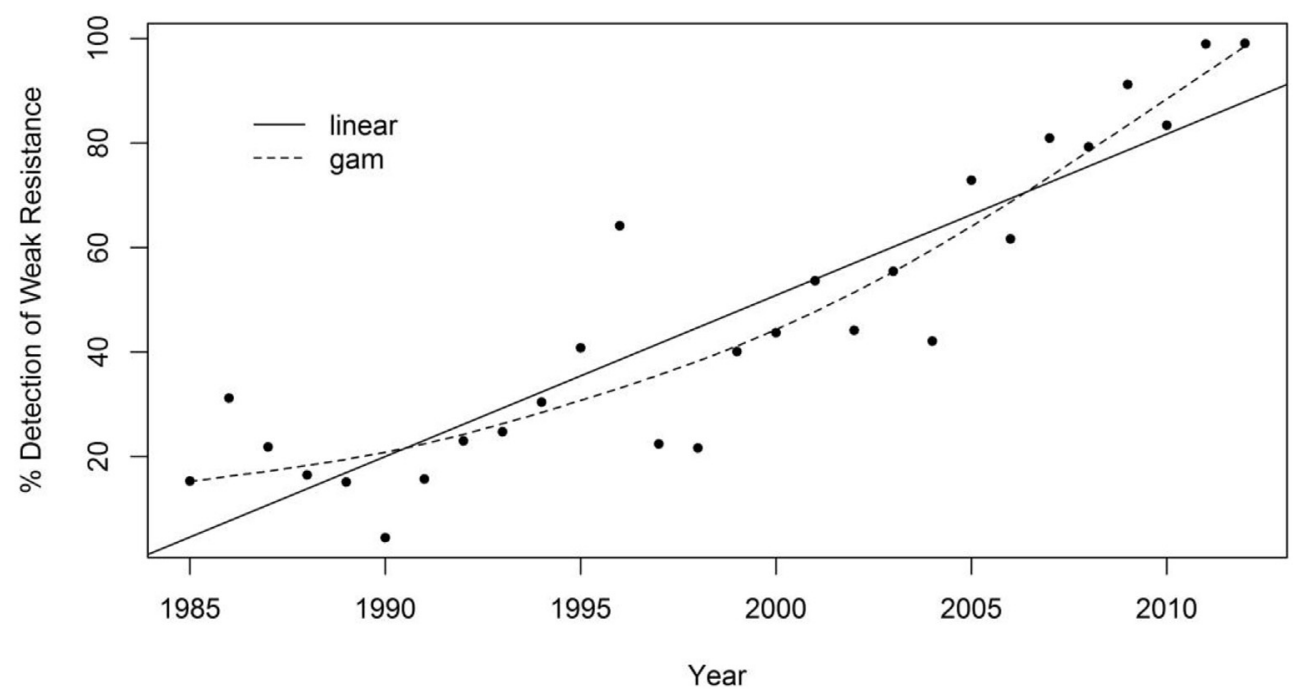

Fig. 3. Linear and smoothed (generalised addition model, GAM) trend analysis of raw weak resistance data aggregated by year collected for T. castaneum across Australia.

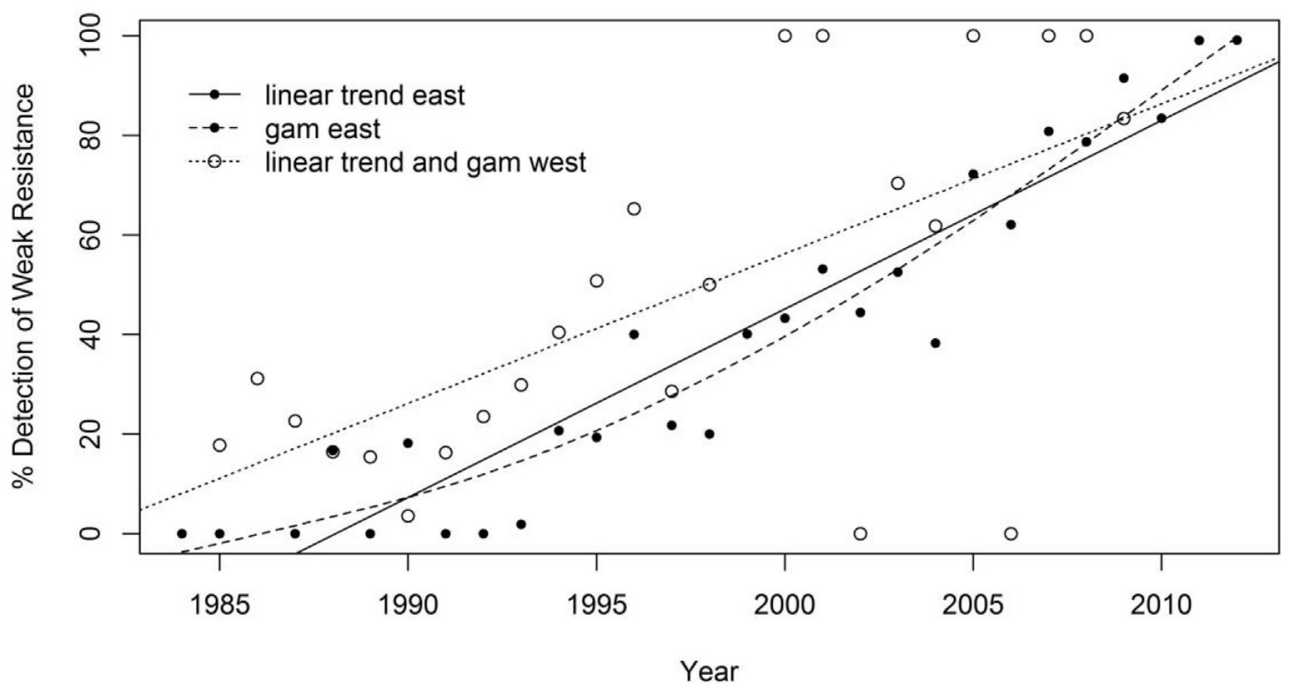

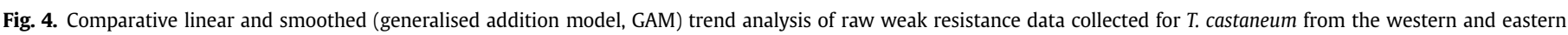
regions of Australia, aggregated by year.

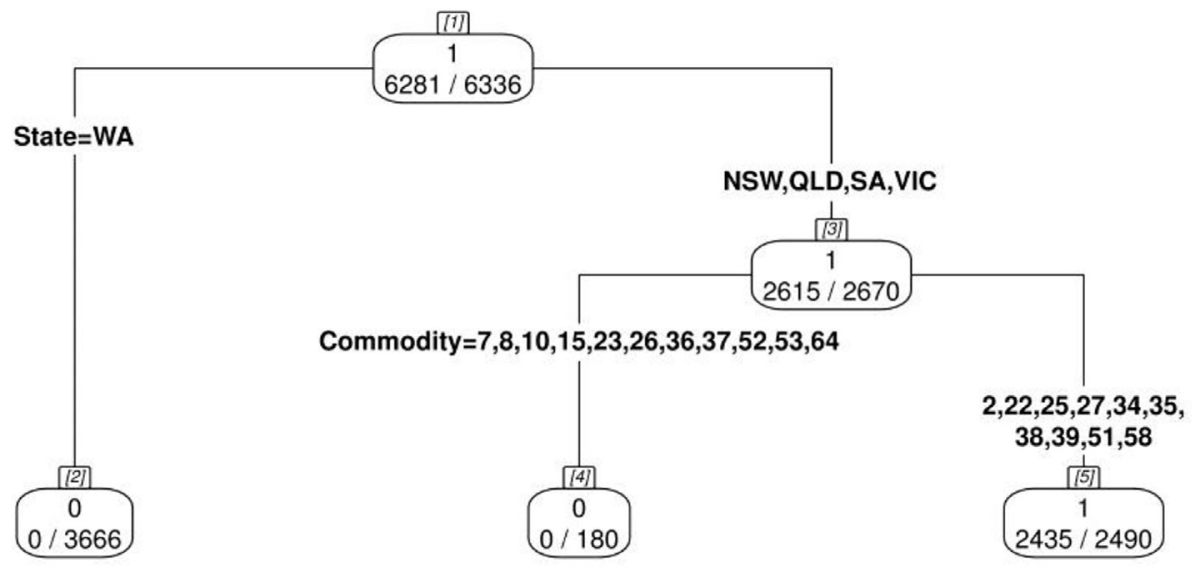

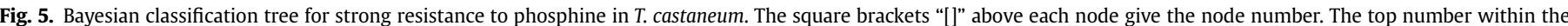

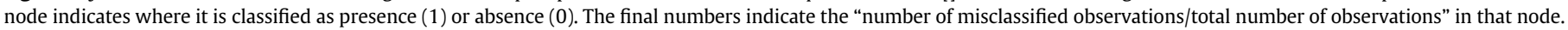
The text on each branch indicates the variable and the levels of that variable that are split down that branch. 


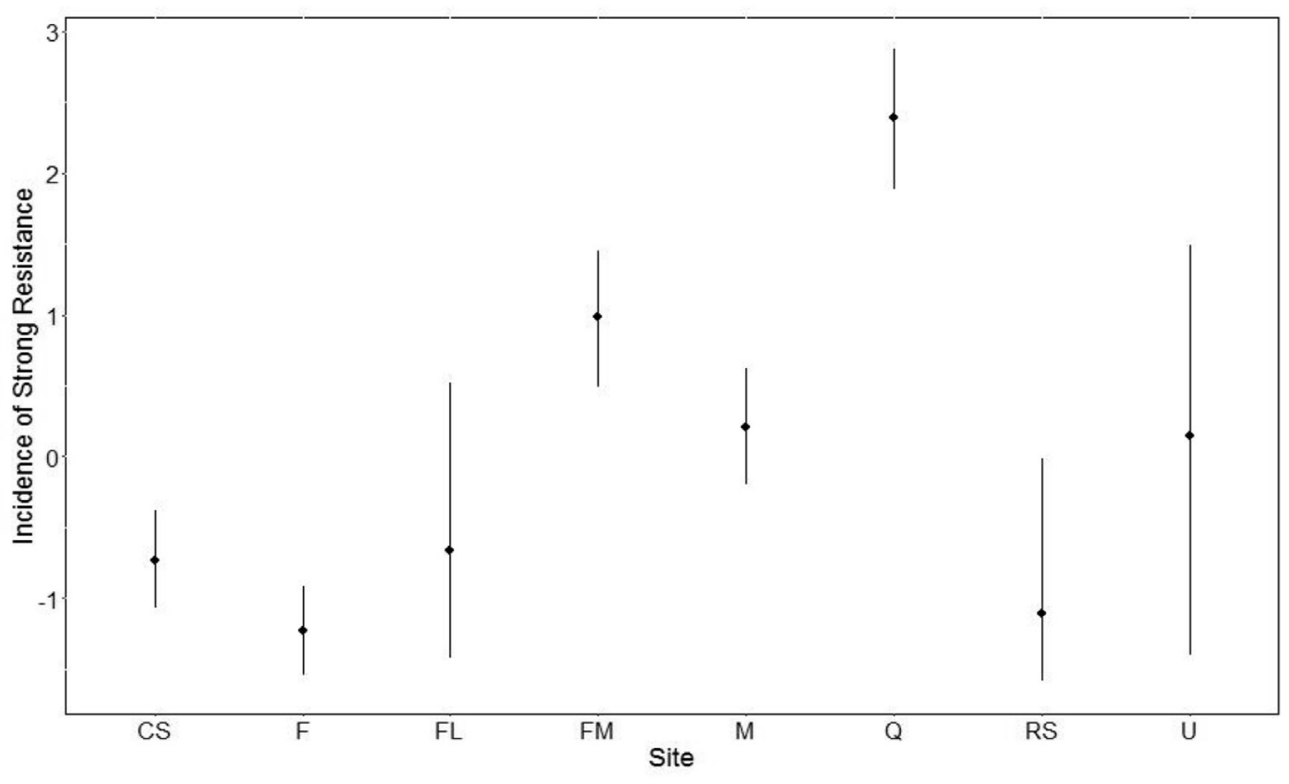

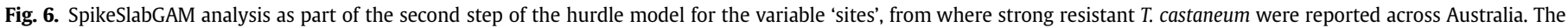

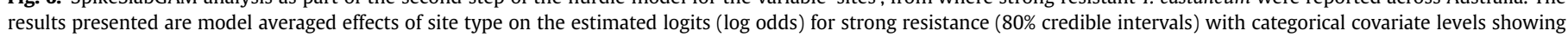
increase or decrease in incidence of strong resistance. The results are inconclusive if the credible intervals cover zero. Refer to appendix for site codes.

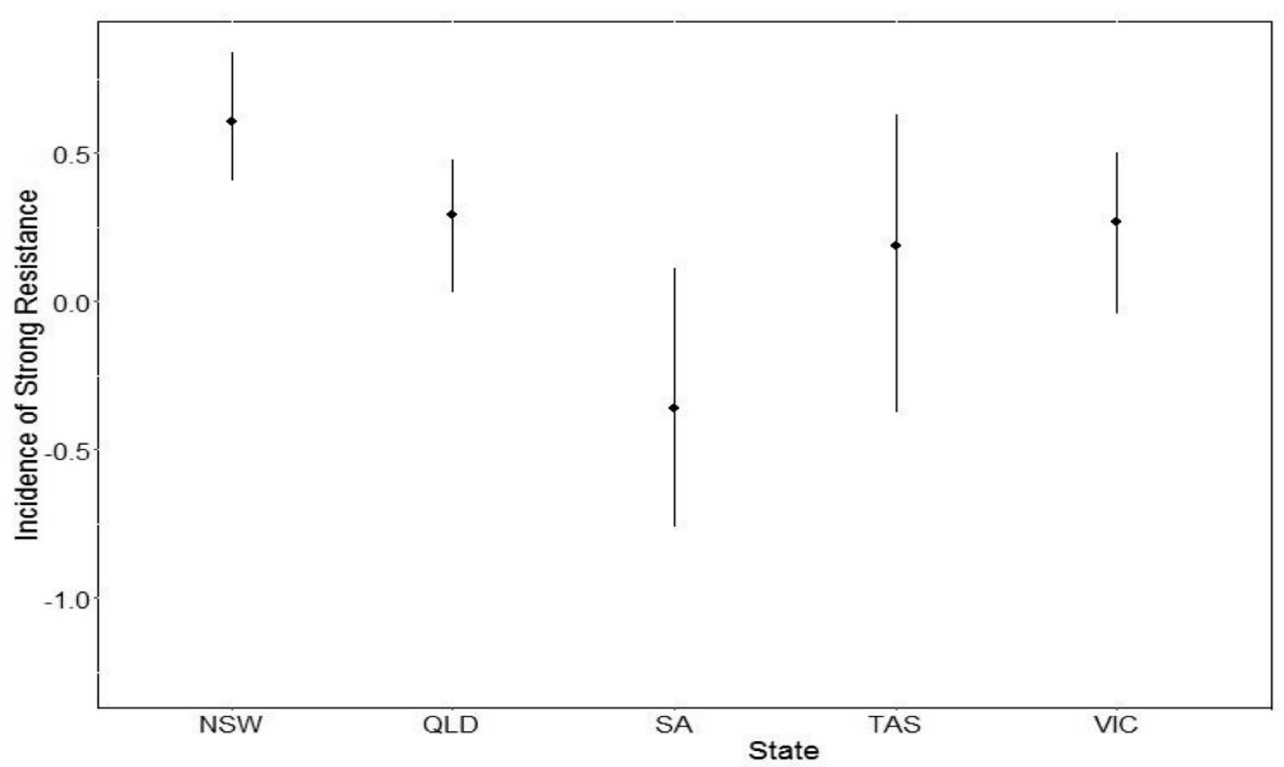

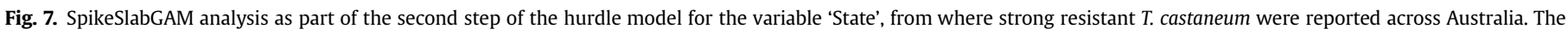

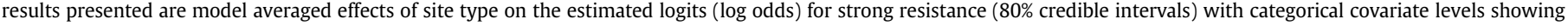
increase or decrease in incidence of strong resistance. The results are inconclusive if the credible intervals cover zero. Refer Appendix for state codes.

Based on results that showed only 62 samples of T. castaneum detected with strong resistance out of 6336 samples tested over the two decades period in Australia, it translates into a significantly lower frequency (below 1\%), compared to the recently published higher frequencies in some overseas countries. For examples, Kaur et al. (2015) reported a very high frequency of $94 \%$ of strong resistance in $T$. castaneum population samples tested from 3 states in southern India; while Opit et al. (2012) and Koçak et al. (2015) have reported a strong resistance frequency of $94 \%$ in several populations tested in Oklahoma in USA and 6 provinces in Turkey, respectively. The significantly lower level of strong resistance frequency in this major pest species in Australia may be attributed to the adoption of a proactive phosphine resistance management strategy that has been developed through consultations among researchers and industry end-users (Collins, 2009).

The overall analysis of the large dataset using descriptive statistics and Baysian Hurdle Model suggests that, irrespective of the variation in factors such as storage type, sites, commodity and treatment history, strong resistance to phosphine in $T$. castaneum has been prevalent in the eastern grain belt of Australia and so far, no strong resistance in this species has been detected in the western region. This is in line with the earlier findings from AGIRD analyses of two other pest species S. oryzae (Holloway et al., 2016) and $R$. dominica (Collins et al., 2017). These recent studies have also established that strong resistance is yet to be detected in these two species in the western region and all such detections have been 


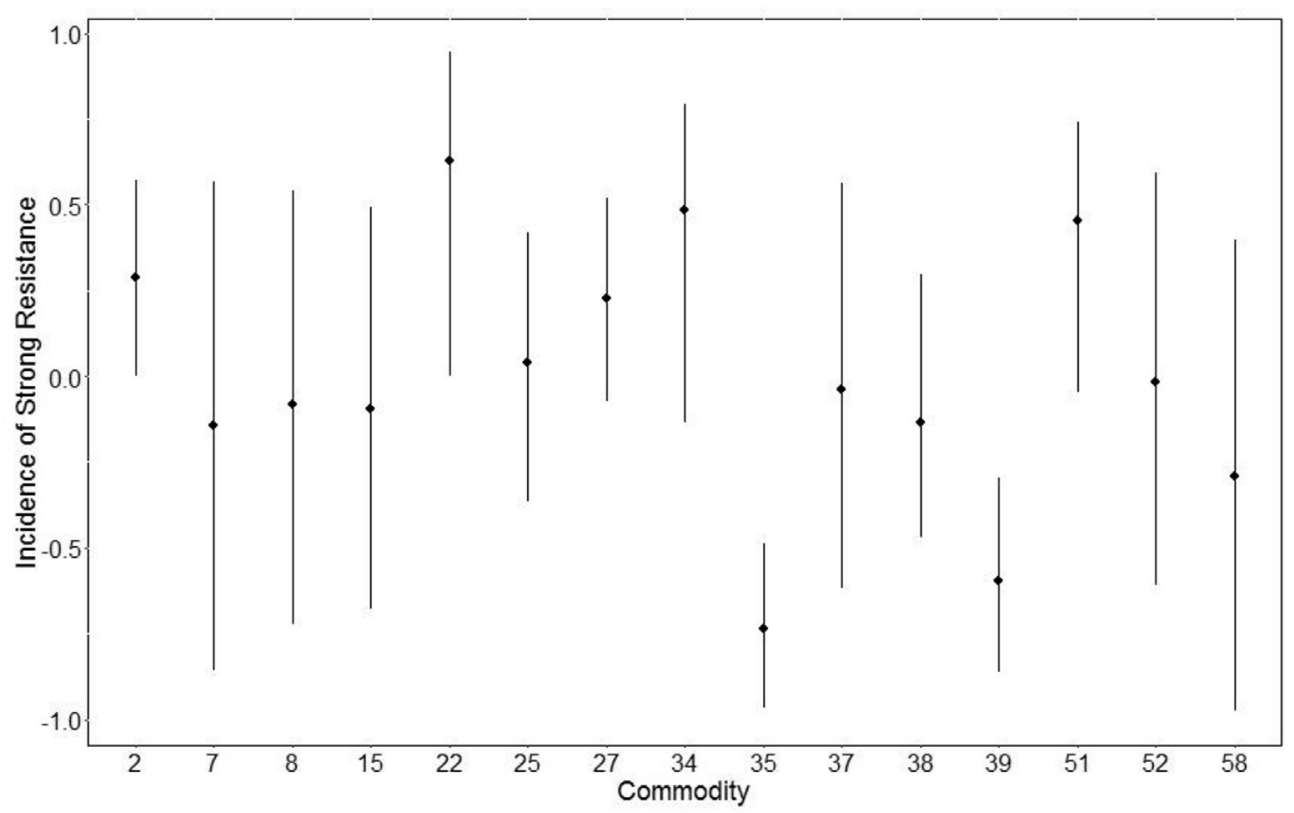

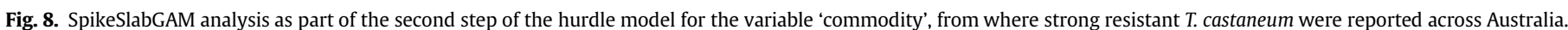

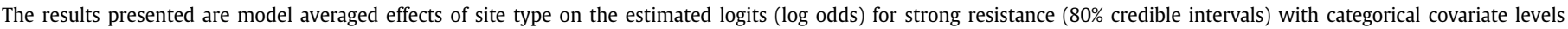
showing increase or decrease in incidence of strong resistance. The results are inconclusive if the credible intervals cover zero. Refer Appendix for commodity codes.

confined to the eastern part of Australia. It is well established that multiple fumigations in leaky structures is the most likely factor that triggers development of resistance to phosphine in the majority of stored grain pests (Collins, 2009). In this context, the Western Australian grain handling system has an advantage over the eastern States in its continuous modernisation of the storage system since the 1980s to make the storage structures sealed has maximised the effectiveness of phosphine fumigation (Emery et al., 2011).

It is noted that while Western Australia had focussed on fumigants and moved away from grain protectants through legislation after the widespread resistance to malathion in the late 1960s, the eastern States have continued to allow the use of grain protectants to manage stored grain pests, which has subsequently prolonged the use of structures that do not require the air-tightness (Emery et al., 2011). Over this period, however, continuous demand for residue-free grain has resulted in a significant shift from use of protectants to phosphine in the eastern states, but without the necessary improvements in sealing the leaky structures. Using these structures for fumigating grain with phosphine has probably contributed significantly towards the development of strong resistance across the eastern grain belt. Moreover, compared to the eastern states, Western Australia has a business model that requires only short-term storage of grain prior to export. Long-term storage of grain in old structures that lack air-tightness may be another factor contributing towards the higher incidences of strong

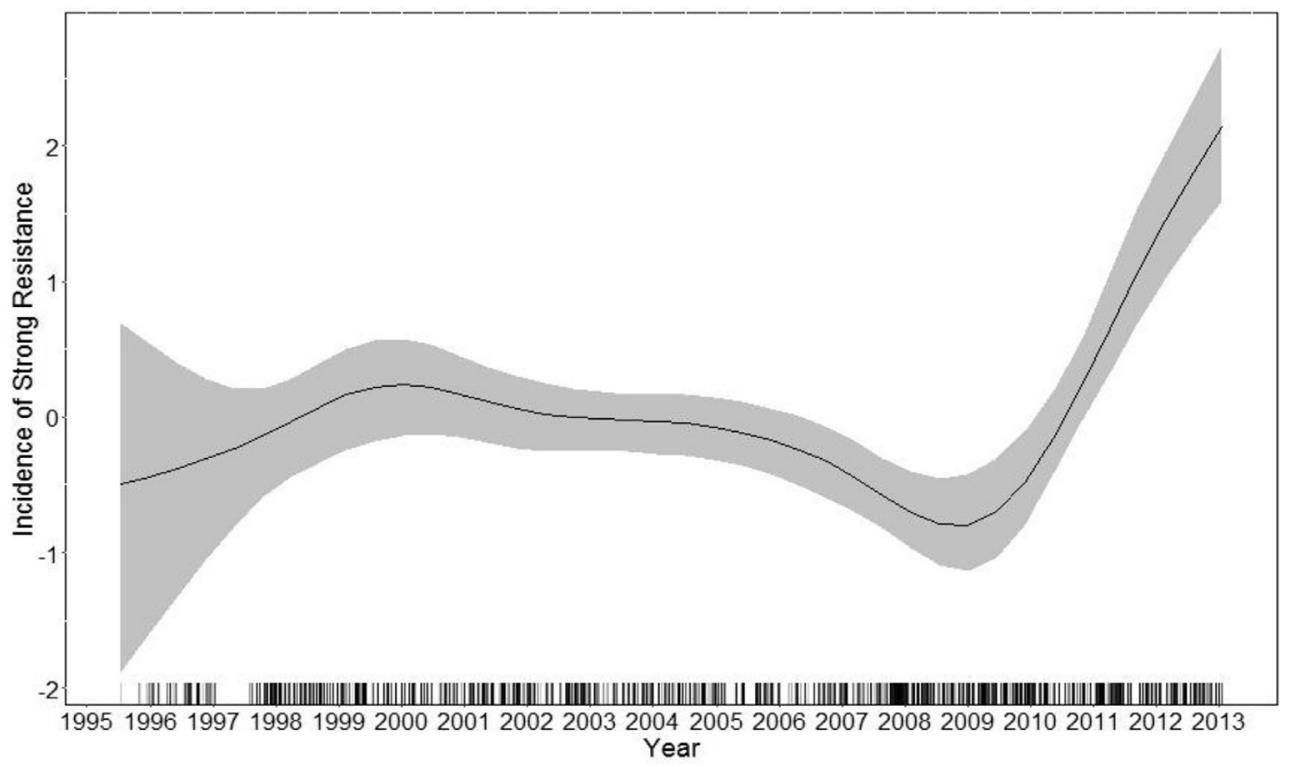

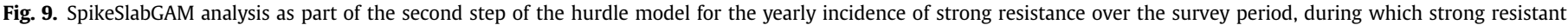

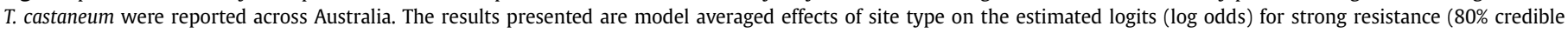
intervals) with categorical covariate levels showing increase or decrease in incidence of strong resistance. The results are inconclusive if the credible intervals cover zero. 


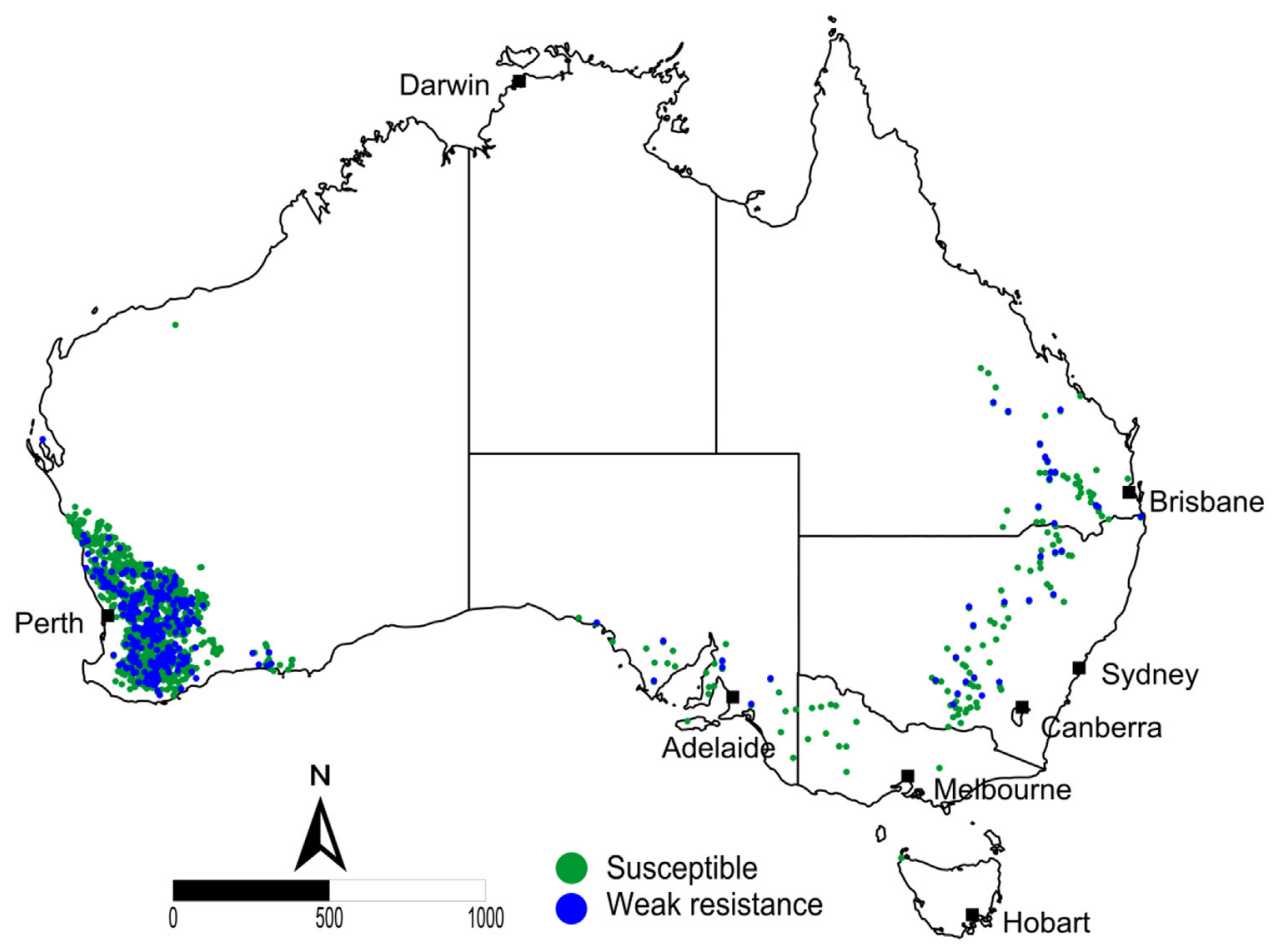

Fig. 10. Distribution of incidences of weak resistance to phosphine in T. castaneum across Australia over the 1990-95 period.

resistance in the eastern states. Long-term storage can also facilitate carry-over of resistant populations from old grain to freshly harvested grain, if adequate disinfestation activities are not undertaken (Collins, 2009). Although the current National Phosphine Resistance Management Strategy (Collins, 2009) suggests complete emptyng of storages prior to loading freshly harvested grain, the logistics and other operational factors often do not allow execution of this approach, particularly in large storage sites.

For the states of Queensland and Victoria, there was no significant difference between regions so far as strong resistance detections for T. castaneum were concerned. For the state of New South Wales, however, there seems to be significant regional differences in strong resistance detections for this species, with Dubbo, Cootamundra and coastal regions recording the highest

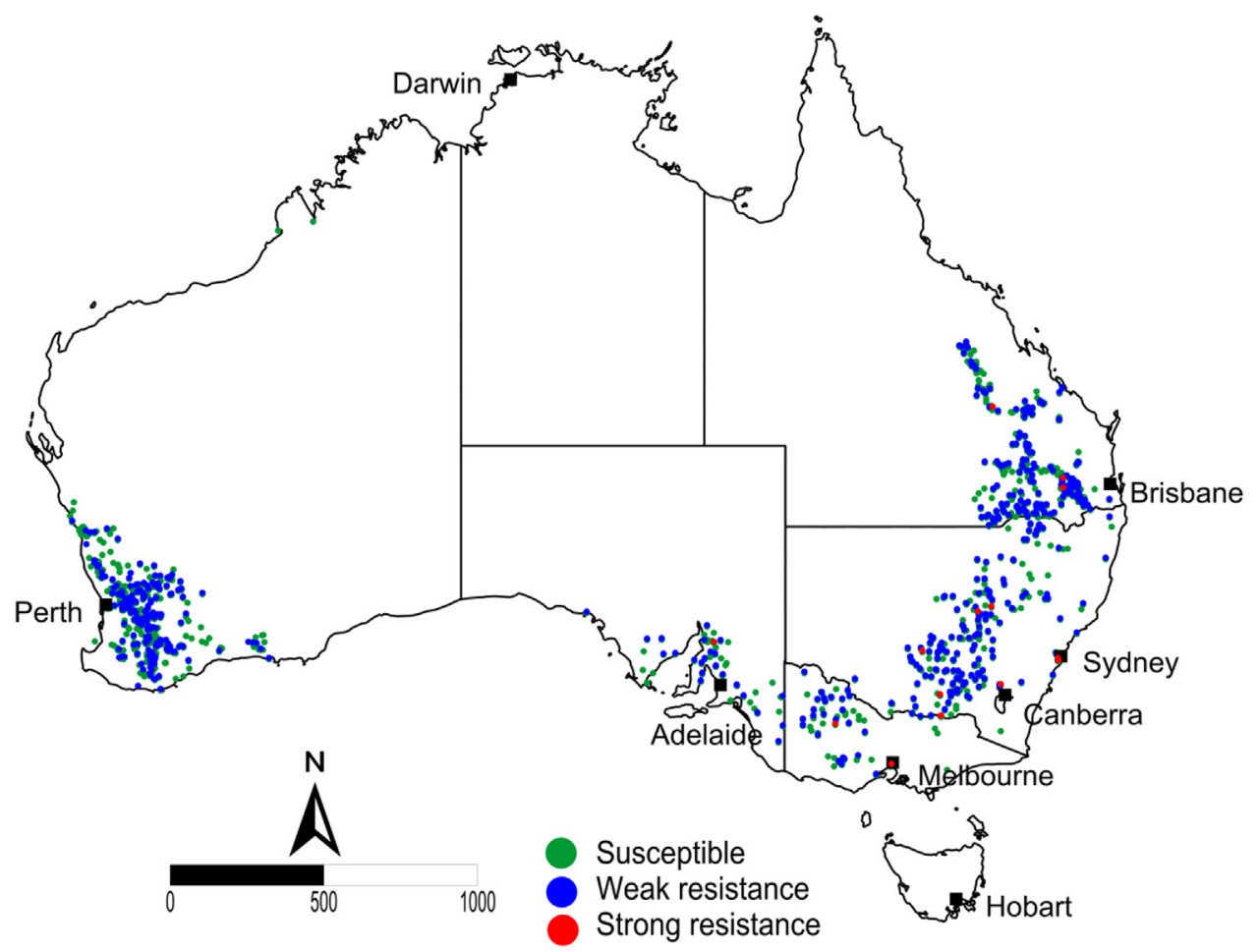

Fig. 11. Distribution of incidences of weak and strong resistance to phosphine in T. castaneum across Australia over the 1996-2001 period. 


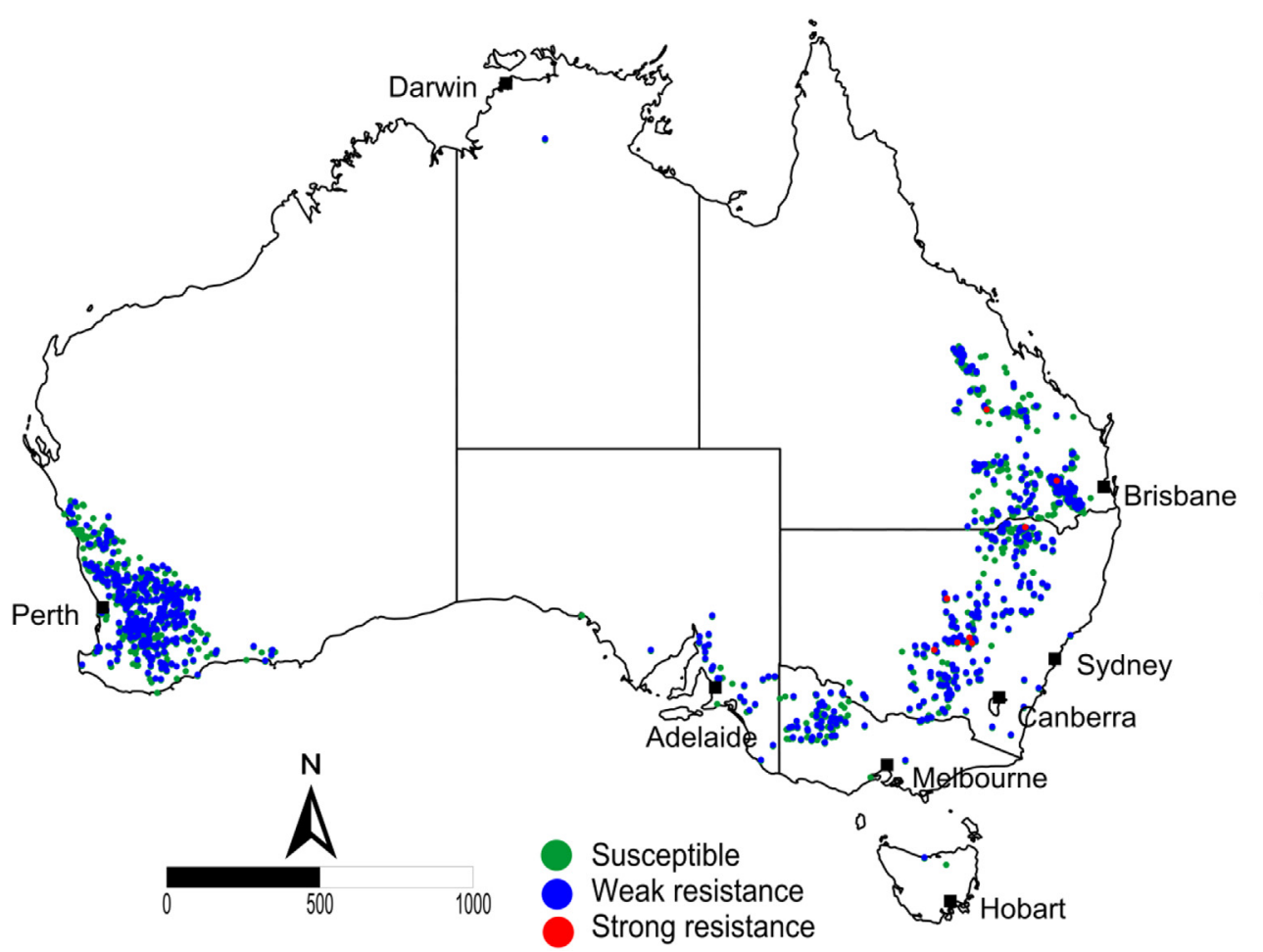

Fig. 12. Distribution of incidences of weak and strong resistance to phosphine in T. castaneum across Australia over the $2002-07$ period.

number of detections over the last two decades. When compared with data generated from the recent analyses of AGIRD for two other key pest species, $R$. dominica (Collins et al., 2017) and S. oryzae
(Holloway et al., 2016), Dubbo in New South Wales also featured prominently for harbouring a significant proportion of the strongly resistant populations of both these species. Compared to the

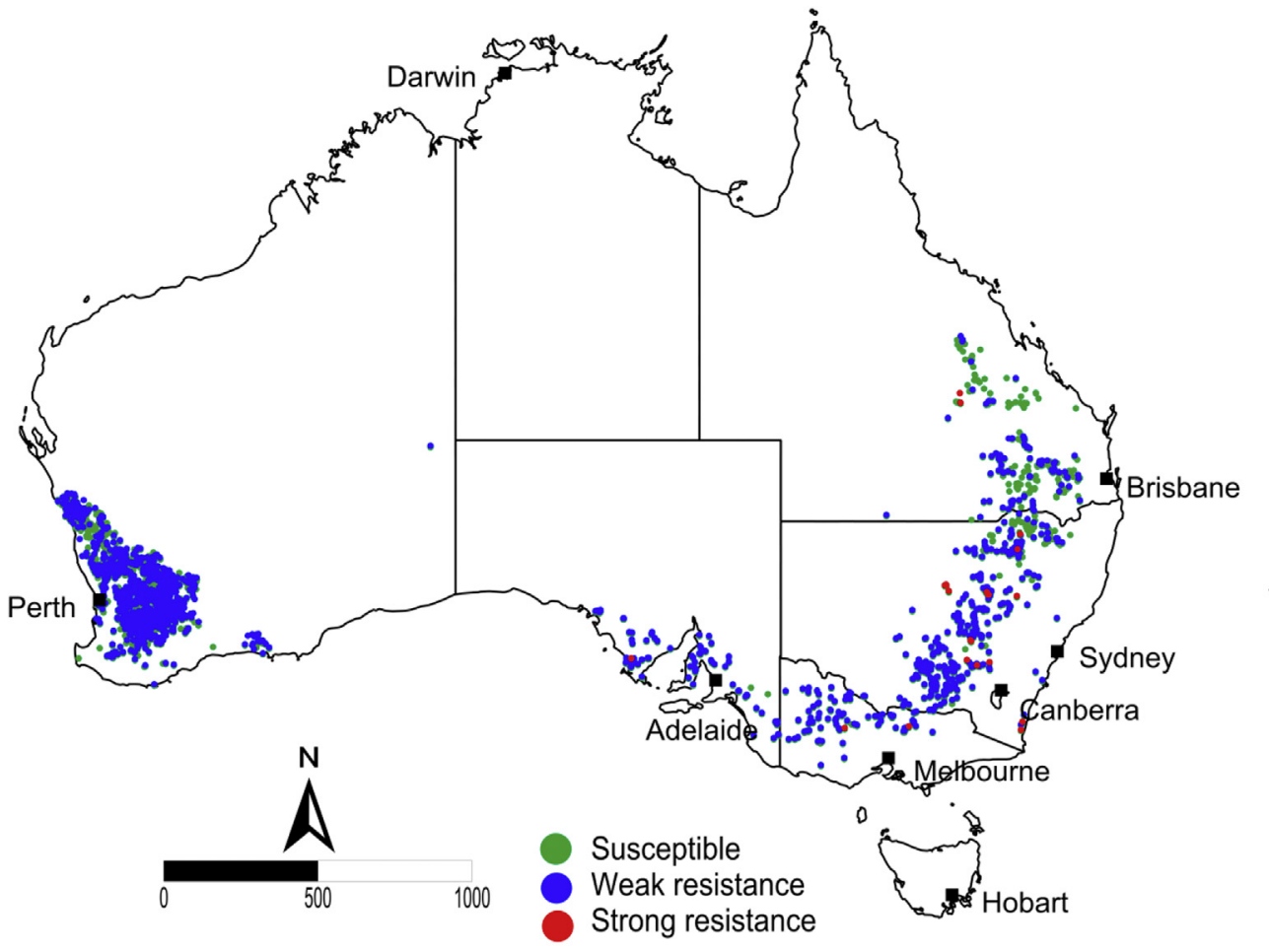

Fig. 13. Distribution of incidences of weak and strong resistance to phosphine in T. castaneum across Australia over the $2008-13$ period. 
southern region, this part of New South Wales is highly productive with a high degree of grain movement including concentration of storage facilities, several of which are not well equipped for fumigation. Holding the grain in storages for a longer period to obtain a high market price sometimes leads to repeated fumigations to control infestations. Along with these, the warm and humid climate may have the contributing factors for the high incidence of insect population growth, specifically in related to the strongly resistant populations.

Among several site types studied, the strong resistance detections in $T$. castaneum were found to be significantly more prevalent in quarantine interceptions than on farm or central storages, two of the dominant sites for collection of pest samples. This is in contrast to the analyses undertaken for $R$. dominica (Collins et al., 2017), for which, strong resistance detections were found to be significantly higher in central storages; and for S. oryzae, for which, farms were considered as the dominant sites for strong resistance detections (Holloway et al., 2016). Although specific data is not available, the high incidences of strong resistant $T$. castaneum populations at quarantine interceptions can be attributed to the reportedly higher frequencies of strongly phosphine resistant populations of this species in overseas countries compared to Australia (Koçak et al., 2015; Kaur et al., 2015). It is important, therefore, that proper detection and resistance diagnosis of any intercepted overseas pest samples be undertaken at ports by quarantine authorities, to ensure that the local industries are protected from incursions of strong resistance problems from not only this species but also from far more destructive species such as the khapra beetle, Trogoderma granarium Everts.

For storage types, we found that strong resistance development in $T$. castaneum was more prevalent in bunkers and unsealed storages, a trend similar to that established for S. oryzae (Holloway et al., 2016) and $R$. dominica (Collins et al., 2017). Typically, in these type of poorly sealed storages, achieving complete control of pest populations by maintaining adequate concentration of any fumigant for the recommended fumigation period has always been challenging, as is ensuring an even flow of the fumigant throughout the grain bulk. Moreover, repeated fumigations to overcome the residual populations that survive the initial fumigation has been normal practice in these storages. As there has been an upward trend in number of strong resistance incidences in $T$. castaneum from 2009 onwards, to reduce these incidences, industry needs to be regularly apprised of the shortcomings of bunkers and unsealed storages so that appropriate resistance management strategies be implemented. These may include extra effort to ensure gastightness of problematic structures prior to fumigation, continuous monitoring of the fumigant throughout the fumigation period and compensation of fumigant if required, capping the total number of fumigations, or use of an effective alternative treatment to phosphine.

We could not establish any significant correlation between strong resistance development and any particular commody that harboured the $T$. castaneum populations during the survey period. However, the highest proportion of strong resistance detections for this species were recorded in samples obtained from processed food and flour, which may be correlated to the poor fumigation facilities in mills that may have encouraged the selection for strong resistance in this species.

There was no correlation with the development of strong resistance in $T$. castaneum with the 16 types of pest treatments that were recorded in AGIRD against the samples of this pest that were analysed in this study. Apart from poor fumigation practices and lack of effective alternatives to phosphine, there are two other factors that may have also contributed towards the strong resistance instances in this species and their distribution over a vast geographic region (roughly $4500 \mathrm{~km}$ from the eastern grain belt to the western grain belt) (Figs. 10-13). There is the potential for resistant insects to be moved within and between regions through grain transport networks (Hernandez Nopsa et al., 2015) and recent research has also demonstrated active flight dispersal of this species away from grain storages (Ridley et al., 2011). Ridley et al. (2011) established significant gene flow between populations, and that dispersing female beetles are mated before leaving the storages and have a high degree of fecundity potential and longevity. All these factors have direct relevance so far as the occurrence and movement of resistant populations within the grain storage ecosystem is concerned. Although Ridley et al. (2011) examined gene flow they did not screen for phosphine resistance genes. Further analysis of trapped insects using molecular diagnostics to identify the presence of resistant genes (Kaur et al., 2015) would be valuable, as would a more systematic analysis of grain transport with methods such as those used by Hernandez Nopsa et al. (2015).

The first detection of strongly phosphine resistant $T$. castaneum in Australia was reported in 1997, the same year as the first detection of strongly resistant lesser grain borer $R$. dominica (Collins et al., 2005). However, there was a significant difference between the strength of resistance in these pest species. The strong resistance in $R$. dominica survived the phosphine label rates of 1997 and threatened the market access of Australian grain that adheres to a 'nil tolerance' mandate for live insects. Proper characterisation of this resistance, manipulation of concentration and exposure profiles, along with the development of new fumigation protocols has led to the modification of the phosphine label to enable industry to successfully control strong resistant populations of R. dominica (Collins et al., 2005; APVMA, 2016). Moreover, there have been significant recent developments in the characterisation of a much stronger level of resistance in the rusty grain beetle, C. ferrugineus requiring newer fumigation protocols being recommended and further revision of the phosphine label (Nayak et al., 2012; Kaur and Nayak, 2015). For T. castaneum, the resistance problem discussed here poses no immediate threat to the grain industry due to the current and the proposed fumigation protocols being able to successfully control these strong resistant populations. The recent successful introduction of sulfuryl fluoride as a 'phosphine resistance breaker' could play an important role in reducing the ongoing selection pressure on phosphine (Nayak et al., 2016).

These data-driven proactive resistance management approaches will help sustain the effective use of phosphine as a key grain disinfestant into the foreseeable future not only in Australia but also in overseas countries that are currently experiencing serious phosphine resistance problems.

\section{Conclusions}

This paper presents analyses of collected data and highlights the advantages of a nationally coordinated phosphine resistance monitoring program that has been essential in providing valuable information and insect materials towards development and implementation of resistant management programs for major stored products pests in Australia. The key findings from this study will contribute towards further modification of the National Phosphine Resistance Management Strategy in Australia (Collins, 2009) and will provide valuable guidance towards establishment of a monitoring program in several overseas countries where phosphine resistance has been reported as a major issue for the grain industry. While new phosphine protocols to manage strongly 
resistant $C$. ferrugineus populations have been submitted to the registration process for a label change, industry has already adopted sulfuryl fluoride as a major resistance intervention tool to break the phosphine resistance cycle, specifically in large central storages (Nayak et al., 2016). In view of the increasing use of sulfuryl fluoride, it is imperative that we prepare ourselves for the future possibility of resistance development to this fumigant in key pest species. Therefore, it is important that research be undertaken to establish species-specific base-line data and resistance monitoring protocols incorporated into AGIRD. Moreover, in view of the significant progress made in recent years in the area of development of 'quick tests' (Nayak et al., 2012) and molecular diagnostics (Schlipalius et al., 2012), it is time that resistance data generated using these diagnostic methods also be incorporated into the AGIRD.

\section{Acknowledgements}

The authors gratefully acknowledge the support of Plant Biosecurity Cooperative Research Centre (Project No: PBCRC3035) established and supported under the Australian Government's Cooperative Research Centre Program (http://www.crcplantbiosecurity.com.au) for undertaking this research. Authors also thank Rajeswaran Jagadeesan for his critical comments on an earlier draft of the manuscript. Continuous support from the Grains Research and Development Corporation (GRDC) since the inception of the National Phosphine Resistance Monitoring Program is also gratefully acknowledged by the authors. We extend our sincere thanks to the staff of major grain bulk handling companies, GrainCorp Ltd., Viterra Ltd. And CBH Group Ltd., and the many growers and their families for access to their properties and storages and for their help during the collection of insect samples. Special thanks to the numerous technical staff, responsible for the collection of field samples and resistance diagnosis over the years including Mrs Hervoika Pavic, Mr Lawrence Smith, Mrs Linda Bond, Mrs. Michelle Chami, Mrs Nuccia Eyres, Mr David Cousins, Mrs Rachel Wood and Mrs Julie Clarke.

\section{Appendix A. Data dictionary}

Commodity codes

\section{Grain storage treatments}

Actellic
Aeration
Bioresmethrin
Carbaryl
Deltamethrin
Dichlorvos
Dryacide
Fenitrothion
Insect growth regulator
None
Other
Phosphine
Phosphine (SIROFLOW ${ }^{\mathbb{R}}$ )
Pyrethrins/minor pyrethroid
Reldan
Unknown

Site type codes

\begin{tabular}{ll}
\hline CS & Central storages \\
F & Farms \\
FL & Feed lot \\
FM & Flour mill \\
H & Household \\
M & Merchants \\
RS & Research station \\
Q & Quarantine \\
U & Unknown \\
\hline
\end{tabular}

State codes

\begin{tabular}{ll}
\hline NSW & New South Wales \\
NT & Northern Territory \\
QLD & Queensland \\
SA & South Australia \\
TAS & Tasmania \\
VIC & Victoria \\
WA & Western Australia \\
\hline
\end{tabular}

Barley
Canola
Chickpeas
Cotton seed
Feed
Lupins
Maize/Corn
Mixed grain
Mung beans
Oats
Processed food
Sorghum
Sunflower
Waste
Unknown
Wheat
Triticale
Peas
Rye
Flour
Saflower
Soybean

Storage type codes

\begin{tabular}{ll}
\hline A & Aerated \\
B & Bunker \\
D & Shed \\
H & Handling equipment \\
I & Silo \\
N & Unknown \\
S & Sealed storage \\
U & Unsealed storage \\
\hline
\end{tabular}

\section{References}

APVMA (Australian Pesticide and Veterinary Medicine Authority), 2016. Product No 69552, Available: http://services.apvma.gov.au (Accessed 15 July 2016).

Benhalima, H., Chaudry, M.Q., Mills, K.A., Price, N.R., 2004. Phosphine resistance in stored-product insects collected from various grain storage facilities in Morocco. J. Stored Prod. Res. 40, 241-249.

Chen, Z., Schlipalius, D., Opit, G., Subramanyam, B., Phillips, T.W., 2015. Diagnostic 
molecular markers for phosphine resistance in U.S. populations of Tribolium castaneum and Rhyzopertha dominica. PLoS One 10 (3), e0121343.

Collins, P.J., 2009. Strategy to Manage Resistance to Phosphine in the Australian Grain Industry. An Initiative of the National Working Party on Grain Protection. Cooperative Research Centre for National Plant Biosecurity Project CRC70096. http://www.graintrade.org.au/sites/default/files/file/Phosphine_Strategy.pdf (Accessed 23 October 2016).

Collins, P.J., Daglish, G.J., Pavic, H., Kopittke, R.A., 2005. Response of mixed-age cultures of phosphine-resistant and susceptible strains of lesser grain borer Rhyzopertha dominica, to phosphine at a range of concentrations and exposure periods. J. Stored Prod. Res. 41, 373-385.

Collins, P.J., Falk, M.G., Nayak, M.K., Emery, R.N., Holloway, J.C., 2017. Monitoring resistance to phosphine in the lesser grain borer, Rhyzopertha dominica, in Australia: a national analysis of trends, storage types and geography in relation to resistance detections. J. Stored Prod. Res. 70, 25-36.

Daglish, G.J., Nayak, M.K., Pavic, H., 2014. Phosphine resistance in Sitophilus oryzae (L.) from eastern Australia: inheritance, fitness and prevalence. J. Stored Prod. Res. 59, 237-244.

Daglish, G.J., Nayak, M.K., Pavic, H., Smith, L.W., 2015. Prevalence and potential fitness cost of weak phosphine resistance in Tribolium castaneum (Herbst) in Eastern Australia. J. Stored Prod. Res. 61, 54-58.

Emery, R.N., Tassone, R.A., 1998. The Australian Grain Insect Resistance Database - a national approach to resistance data management. In: Banks, H. J., Wright, E. J., Damcevski, K. A. (Eds), Stored Grain in Australia. Proceedings of the Australian Postharevest Technical Conference, Canberra, 26-29 May, 1998, pp. 312-324.

Emery, R.N., Nayak, M.K., Holloway, J.C., 2011. Lessons learned from phosphine resistance monitoring in Australia, 2011 Stewart Postharvest Rev. 7 (3). http:// dx.doi.org/10.2212/spr.2011.3.6.

Falk, M.G., O'Leary, R., Nayak, M.K., Collins, P.J., Low-Choy, S., 2014. A Bayesian hurdle model for analysis of an insect resistance monitoring database. Environ. Ecol. Stat. 22, 207-226.

FAO, 1975. Recommended methods for the detection and measurement of resistance of agricultural pests to pesticides: tentative method for adults of some major pest species of stored cereals, with methyl bromide and phosphine - FAO Method No. 16. FAO Plant Prot. Bull. 23, 12-26.

Gelman, A., Carlin, J.B., Stern, H.S., Dunson, D.B., Vehtari, A., Donald, B., Rubin, D.B., 2013. Bayesian Data Analysis, third ed. CRC Press, London.

Hernandez Nopsa, J.F., Daglish, G.J., Hagstrum, D.W., Leslie, J.F., Phillips, T.W., Scoglio, C., Thomas-Sharma, S., Walter, G.H., Garrett, K.A., 2015. Ecological networks in stored grain: identifying key nodes for emerging pests and mycotoxins in postharvest networks. Bioscience 65, 985-1002.

Holloway, J.C., Falk, M.G., Emery, R.N., Collins, P.J., Nayak, M.K., 2016. Resistance to phopshine in Sitophilus oryzae in Australia: a national analysis of trends and frequencies over time and geographic spread. J. Stored Prod. Res. 69, 129-137.

Kaur, R., Subbarayalu, M., Jagadeesan, R., Daglish, G.J., Nayak, M.K., Naik, H.R., Ramasamy, S., Subramanian, C., Ebert, P.R., Schlipalius, D.I., 2015. Phosphine resistance in India is characterised by a dihydrolipoamide dehydrogenase variant that is otherwise unobserved in eukaryotes. Heredity 115, 188-194.

Kaur, R., Nayak, M.K., 2015. Developing effective fumigation protocols to manage strongly phosphine-resistant Cryptolestes ferrugineus (Stephens) (Coleoptera: Laemophloeidae). Pest Manag. Sci. 71, 1297-1302.

Koçak, E., Schlipalius, D., Kaur, R., Tuck, A., Ebert, P., Collins, P., Yılmaz, A., 2015 Determining phosphine resistance in rust red flour beetle, Tribolium castaneum (Herbst.) (Coleoptera : Tenebrionidae) populations from Turkey. Turkish J. Entomol 39, 129-136.

Lorini, I., Collins, P.J., Daglish, G.J., Nayak, M.K., Pavic, H., 2007. Detection and characterisation of strong resistance to phosphine in Brazilian Rhyzopertha dominica (F.) (Coleoptera: Bostrychidae). Pest Manag. Sci. 63, 358-364.

Nayak, M.K., Daglish, G.J., Phillips, T.W., 2015. Managing resistance to chemical treatments in stored products pests. Stewart Postharvest Rev. 11 (1), 1-6 (6).

Nayak, M.K., Jagadeesan, R., Kaur, R., Daglish, G.J., Reid, R., Pavic, H., Smith, L.W., Collins, P.J., 2016. Use of sulfuryl fluoride in the management of strongly phosphine-resistant insect pest populations in bulk grain storages in Australia. J. Grain Storage Res. 2016, 100-107. http://dx.doi.org/10.5958/09748172.2016.00030.4.

Nayak, M.K., Holloway, J.C., Emery, R.N., Pavic, H., Bartlet, J., Collins, P.J., 2012. Strong resistance to phosphine in the rusty grain beetle Cryptolestes ferrugineus (Stephens) (Coleoptera: Laemophloeidae): its characterisation, a rapid assay for diagnosis and its distribution in Australia. Pest Manag. Sci. 69, 48-53.

O'Leary, R., 2008. Informed Statistical Modelling of Habitat Suitability for Rare and Threatened Species. PhD thesis. Queensland University of Technology, Brisbane.

Opit, G.P., Phillips, T.W., Aikins, M.J., Hasan, M.M., 2012. Phosphine resistance in Tribolium castaneum and Rhyzopertha dominica from stored wheat in Oklahoma. J. Econ. Entomol. 105, 1107-1114.

Pimental, M.A.G., Farroni, L.R.D.'A., da Silva, F.H., Batista, M.D., Guedes, R.N.C., 2010. Spread of phosphine resistance among Brazilian populations of three species of stored product insects. Neotropical. Entomol. 39, 101-107.

R Core Team, 2015. R: a Language and Environment for Statistical Computing. R Foundation for Statistical Computing, Vienna. URL. https://www.R-project.org/.

Ridley, A.W., Hereward, J.P., Daglish, G.J., Collins, P.J., Raghu, S., Walter, G.H., 2011. The spatiotemporal dynamics of Tribolium castaneum (Herbst): adult flight and gene flow. Mol. Ecol. 1635-1646.

Schlipalius, D.I., Valmas, N., Tuck, A.G., Jagadeesan, R., Ma, L., Kaur, R., Goldinger, A., Anderson, C., Kuang, J., Zuryn, S., Mau, Y.S., Cheng, Q., Collins, P.J., Nayak, M.K., Schiarra, H.J., Hillard, M.A., Ebert, P.R., 2012. A core metabolic enzyme mediates resistance to phosphine gas. Science 338, 807-810.

Scheipl, F., 2011. Spikeslabgam: Bayesian variable selection, model choice and regularization for generalized additive mixed models in R. J. Stat. Softw. 43, $1-24$.

White, G.G., Lambkin, T.A., 1990. Baseline responses to phosphine and resistance status of stored-grain beetle pests in Queensland, Australia. J. Econ. Entomol. 83, 1738-1744.

Wood, S.N., 2006. Generalized Additive Models: an Introduction with R. CRC Press, London.

Zettler, J.L. 1990. Phosphine resistance in stored products pests in the United States. In: Fleurat-Lessard, F., Ducom, P. (eds). Proceedings 5th International working conference on stored-product protection. Bordeaux France, September 9-14, 1990, pp. 1075-1081. 